\title{
QUALIDADE MICROBIOLÓGICA DO QUEIJO MINAS FRESCAL COMERCIALIZADO NO MUNICÍPIO DE JABOTICABAL, SP, BRASIL
}

\section{B.M. Salotti ${ }^{1 *}$, A .C .F.B. Carvalho ${ }^{1}$, L.A. A maral' ${ }^{1}$, A.M .C. V idal-M artins' ${ }^{2}$ A .L. Cortez ${ }^{1}$}

${ }^{1}$ Universidade Estadual Paulista, Faculdade de Ciências Agrárias e Veterinárias, Via de Acesso Prof. Paulo Donato Castellane s/no, CEP 14884-900, Jaboticabal, SP Brasil. E-mail -salottibm@hotmail.com

\section{RESUMO}

No período de julho a dezembro de 2002, foi avaliada a qualidade microbiológica de 60 amostras de queijo minas frescal, através do Número Mais Provável (NMP) de coliformes fecais, contagem de Staphylococcus coagulase positiva, pesquisa de Salmonella spp., pesquisa de Listeria monocytogen es e pesquisa deCampylobacter spp., sendo que, 30 amostras eram de produção artesanal e 30 de produção industrial fiscalizadas pelo Serviço de Inspeção Estadual e Federal e foram adquiridas no comércio do Município de Jaboticabal, São Paulo. Quanto a presença de coliformes fecais, apresentaram-se em desacordo com o estabelecido pela Agência Nacional de Vigilância Sanitária (ANVISA) 83,4\% das amostras artesanais e para as amostras industriais 66,7\%. Para os valores obtidos na contagem deStaphylococcus coagulase positiva, $20 \%$ das amostras artesanais e $10 \%$ das amostras industriais, apresentaram-se em desacordo com o estabelecido pela Anvisa. Com relação a detecção de Salmonella spp., Listeria monocytogenes e Campylobacter spp., tais microrganismos não foram isolados em $25 \mathrm{~g}$ do produto, mostrando que em relação a estes agentes os queijos analisados tanto de produção artesanal como os industrializados, apresentaram-se dentro dos padrões estabelecidos (ausência em $25 \mathrm{~g}$ do produto). Os resultados microbiológicos revelaram que $86,7 \%$ das amostras artesanais e 66,7\% das amostras industriais encontravam-se em desacordo com os padrões estabelecidos pela Anvisa, segundo a Resolução n ${ }^{\circ} 12$ de 02 de janeiro de 2001. Tais resultados demonstram o risco potencial que este produto pode representar para a saúde da população consumidora.

PALAVRAS-CHAVE: Queijo minas frescal, qualidade microbiológica, saúde pública.

\section{ABSTRACT}

MICROBIALQUALITY OF MARKETABLE "MINAS FRESCAL" CHEESE IN JABOTICABAL, SP, BRAZIL. From July to December 2002 the microbial quality of 60 samplesnofinasfrescal" cheese was analyzed, from which 30 hand made samples and 30 from dairy industry inspected by Federal Inspection Service. The microbiological results revealed that $86.7 \%$ from hand-made samples and $66.7 \%$ from dairy industry samples were not in standards permitted by the current legislation (Agência Nacional de Vigilância Sanitária - ANVISA), according to resolution number 12 of January 2nd, 2001. Of the hand made and dairy industry samples, $83.4 \%$ and $66.7 \%$ $\left(>5.0 \times 10^{2} \mathrm{MPN} / \mathrm{g}\right)$, respectively, were out of the standards for contamination by fecal colliforms. The values obtained by coagulase positive staphylococci count, $20 \%$ of the hand made samples and $10 \%$ of the dairy industry samples were not accordind to the standards permitted $\left(5.0 \times 10^{2} \mathrm{CFU} / \mathrm{g}\right)$. As for Salmonella spp., Listeria monocytogen es and Campylobacter spp., they were not detected in $25 \mathrm{~g}$ of the product, showing that, concerning these organisms, both sources of samples were according to ANVISA standards (absence in $25 \mathrm{~g}$ of the product). Our results reveal the potential risk to public health of the marketable "minas frescal" cheese when sanitation care is deficient.

KEY WORDS: "Minas frescal" cheese, microbial quality, health public.

\footnotetext{
${ }^{2}$ Médico Veterinário autônomo, Jaboticabal, SP Brasil.
}

*Doutorando em medicina veterinária. 


\section{INTRODUÇÃO}

No Brasil existem vários tipos de queijos frescos produzidos de forma artesanal e industrial, tanto por pequenos produtores quanto por algumas indústrias. Esses queijos são muito populares e devido ao bom rendimento que proporcionam na fabricação, são comercializados a preços acessíveis a uma maior faixa da população (SENA et al., 2000).

Segundo Almeida Filho(1999) 46\% de toda produção brasileira de leite é comercializada sem qualquer tipo de fiscalização oficial, que observou um consumo anual de aproximadamente 415 mil toneladas de queijo, sendo 200 mil toneladas não inspecionadas compostas basicamente pelo queijo minas frescal (ANUALPEC, 1998).

Segundo o Regulamento Técnico de Identidade e Qualidade de Produtos Lácteos (BRASIL, 1997) entende-se por queijo minas frescal, o queijo fresco obtido porcoagulação enzimática do leite com o coalho e/ou outras enzimas coagulantes apropriadas, complementada ou não com a ação de bactérias lácticas específicas. Seguindo a orientação contida nesse regulamento, os queijos tipo minas podem ser classificados em queijos de baixa umidade ou de massa semidura, com umidade entre 36,0 e $45,9 \%$, queijos de alta umidade ou de massa branda ou "macios", com 46,0 a $54,9 \%$ de umidade e queijos de muita alta umidade ou de massa branda ou "mole", com umidade não inferior a $55,0 \%$.

Oqueijo minas frescal também pode ser classificado segundo a Agência Nacional de Vigilância Sanitária - Anvisa (BRASIL, 2001) de duas formas: de alta umidade $(46 \%)$ ou de muita alta umidade $(55 \%)$ com bactérias lácticas abundantes e viáveis; e também de muita alta umidade (55\%) elaborados por coagulação enzimática, sem a ação de bactérias lácteas (incluindo o minas frescal correspondente).

O queijo caseiro minas frescal por apresentar elevado teor de umidade, ser produto altamente perecível e passar por uma grande manipulação, apresenta condições propícias para contaminação, sobrevivência e multiplicação bacteriana e muitas dessas bactérias podem ser patogênicas ou produzir metabólitos microbianos e causar intoxicações e/ou infecções alimentares nos seres humanos (CÂMARA et al., 2002).

Apesar das exigências para que o leite destinado a fabricação de queijos seja higienizado por meios físicos e submetidos à pasteurização, é intensa a comercialização dos queijos que não passam por tais especificações. Além disso, a contaminação do leite pós-pasteurização, a utilização de fermentos inativos, temperaturas inadequadas e incorretas condições de manufatura e armazenagem, contribuem também de forma efetiva para o comprometimento da qualidade do produto final (PERERA et al., 1999).
Apesar da proibição legal imposta à comercialização de queijos frescos e moles, elaborados a partir do leite cru no Brasil, a venda do queijo minas frescal produzido artesanalmente tem sido realizada abertamente em nosso meio, especialmente nos Estados de Minas Gerais e São Paulo. Inúmeras indústrias sob inspeção por órgãos competentes produzem o queijo minas frescal respeitando as normas vigentes, inclusive as de boas práticas de fabricação, buscando a obtenção de um produto compatível com o padrão de qualidade estabelecido ( AlmEIDA FilHo, 1999).

Em termos gerais, dentro do campo da microbiologia de alimentos, sem dúvida as contaminações microbianas dos alimentos são indesejáveis e inclusive nocivas. Este aspecto é encarado com tal rigor que para se conhecer a existência de possíveis deficiências higiênicas, as quais implicariam em contaminações alimentares, voltam-se as atenções para grupos de microrganismos, desde aqueles considerados indicadores, como também para os patogênicos que encontram no alimento um meio propício para o desenvolvimento e até mesmo a liberação de substâncias tóxicas (Franco \& Almeida, 1992).

Dentre alguns microrganismos importantes em alimentos destacamos: a Salmonella spp., causadora de intoxicação alimentar; aE scherichiacoli, que possui sorogrupos cuja patogenicidade é conhecida através da ação toxigênica e infecciosa e o Staphylococcus aureus, que é toxigênico e produtor de toxina termoestável pré formada no alimento. Em 2000, segundo pesquisa realizada por CÂMARA et al. (2002), esses microrganismos foram responsáveis por $37,5 \%$, $50 \%$ e $37,5 \%$, respectivamente, dos 8 surtos confirmados; sendo identificadosStaphylococcus aureus, 33,3\% foi em queijo minas frescal artesanal.

O presente trabalho objetivou avaliar a qualidade microbiológica do queijo minas frescal produzido artesanalmentee inspecionado pelo Serviço de Inspeção Estadual e Federal, através da quantificação dos Coliformes fecais, Staphylococcuscoagulase positiva e pesquisas de Salmonella spp., Listeria monocytogenes e Campylobacter spp. Posteriormente, tais resultados foram utilizados para comparar a qualidade dos produtos segundo a legislação vigente.

\section{MATERIAL E MÉTODOS}

Foram analisadas 60 amostras de queijo minas frescal (de muita alta umidade, 55\%, elaborados por coagulação enzimática, sem a ação de bactérias lácticas), sendo que 30 destas amostras eram inspecionadas pelo Serviço de Inspeção Estadual e Federal e 30 amostras eram artesanais, comercializadas em supermercados, padarias, açou- 
gues e feiras livres no Município de Jaboticabal, SP. Cada amostra, adquirida aleatoriamente no período de julho a dezembro de 2002, foi representada por uma peça do produto, sendo que as amostras de origem artesanal estavam envolvidas por uma embalagem plástica, fechada com um feixe metálico não contendo nesta qualquer informação sobre seu conteúdo, origem, data de fabricação e/ou validade. As amostras inspecionadas eram vendidas sob refrigeração e embaladas à vácuo e contendo as devidas informações nas embalagens. Tomou-se o cuidado de adquirir amostras dentro do prazo de validade estipulado nas embalagens.

Durante o transporte as amostras foram mantidas em caixas isotérmicas com cubos de gelo para evitar a ação do calor sobre o produto e as análises imediatamente realizadas após sua chegada ao laboratório ao Laboratório de Microbiologia de Alimentos e Água do Departamento de Medicina Veterinária Preventiva e Reprodução Animal da Faculdade de Ciências Agráriase Veterinárias Unesp, Câmpus de Jaboticabal.

Determinação do número mais provável de coliformes fecais por grama (NMP/g) (APHA, 1992)

Foram selecionadas 3 diluições adequadas da amostra e transferidos $1 \mathrm{~mL}$ para tubos contendo caldo lauril sulfato triptose (LST) que continham tubos de Duhran invertidos. Após incubação a $35^{\circ} \mathrm{C}$ durante $48 \mathrm{~h}$, dos tubos positivos, que apresentaram produção de gás, foi transferida uma alçada para dois tubos, um contendo caldo lactosado verde brilhante bile, incubado a $35^{\circ} \mathrm{C}$ durante $48 \mathrm{~h}$, para verificar a presença de coliformes totais e outro contendo caldo EC, incubado em banho-maria a $44,5^{\circ} \mathrm{C}$ durante $24 \mathrm{~h}$ para detectar aE. coli. Os tubos que turvam e apresentaram produção de gás, foram considerados positivos e a leitura realizada através da tabela de Hoskin.

Contagem de Staphylococcus coagulase-positiva (APHA, 1992)

Foram selecionadas 3 diluições da amostra, das quais $0,1 \mathrm{~mL}$ foi semeado na superfície de placas contendo ágar Baird-Parker, o inóculo foi espalhado com o auxílio da alça de Drigaslky, as placas invertidas e incubadas a $35^{\circ} \mathrm{C}$ durante $48 \mathrm{~h}$. A partir das colônias típicas foram realizadas as provas de catalase e coagulase.

Pesquisa de Salmonella spp. (APHA, 1992)

$25 \mathrm{~g}$ de cada amostra foram transferidos para frascos contendo $225 \mathrm{~mL}$ de caldo de pré-enriquecimento e incubados a $42^{\circ} \mathrm{C}$ durante 18 a $24 \mathrm{~h}$. Posteriormente, foi realizado o enriquecimento seletivo, com $1 \mathrm{~mL}$ da amostra foi transferida para 2 tubos, um contendo caldo selenito cistina (SC) e outro caldo Rappaport Vassiliadis (RV), incubados a $42^{\circ} \mathrm{C} \mathrm{du}-$ rante $24 \mathrm{~h}$. O plaqueamento diferencial foi realizado a partir dos tubos incubados, semeando através de estrias uma alçada do caldo SC na superfície do ágar verde-brilhante vermelho-de-fenol-lactose-sacarose e outra alçada em ágar Mac Conckey, seguindo o mesmo procedimento com o caldo RV.

\section{D etecção de Listeria monocytogenes, foi utiliza- do o "kit" TECRA ${ }^{\circledR}$}

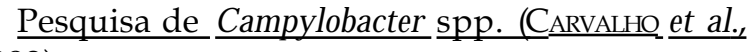
1992)

$25 \mathrm{~g}$ de cada amostra foram adicionados a $225 \mathrm{~mL}$ de água Peptona estéril os frascos foram incubados a $42^{\circ} \mathrm{C}$ durante $24 \mathrm{~h}$. Após a incubação foram transferidas duas alíquotas de $50 \mathrm{~mL}$ em tubos que foram para centrífuga refrigerada por $30 \mathrm{~min}$ a 8.000 $\mathrm{rpm}$, o sedimento mais $2 \mathrm{~mL}$ do sobrenadante foram homogeneizados e semeados em placas contendo ágar Brucela Sangue adicionado de suplemento FBP $(0,025 \mathrm{~g}$ de sulfato ferroso; $0,025 \mathrm{~g}$ de piruvato de sódio; $0,025 \mathrm{~g}$ de metassulfito de sódio), acrescido de $2 \mathrm{~mL}$ de uma mistura de antibióticos $(10 \mathrm{ìg} / \mathrm{mL}$ de vancomicina, $5 \mathrm{ig} / \mathrm{mL}$ de trimethoprim, 2,5 UI/ $\mathrm{mL}$ de polimixina, $5 \mathrm{ìg} / \mathrm{mL}$ de anfotericina B e $15 \mathrm{ìg} / \mathrm{mL}$ de cefalotina e adicionado de $7 \%$ de sangue desfibrinado de carneiro), as placas foram incubadas em jarras para cultivo em anaerobiose com atmosfera microaerófila obtida pelo método de lã de aço, conforme técnica descrita por MAGALHÃes et al. (1982) $42^{\circ} \mathrm{C}$ durante $48 \mathrm{~h}$. As colônias típicas foram submetidas à coloração de Gram para confirmação d€ ampylobacter spp.

\section{RESULTADOS E DISCUSSÃO}

Na Tabela 1 são apresentados o número mais provável (NMP/g) de coliformes fecais e número de amostras de queijo minas frescal, produzidos artesanalmente e inspecionado com fiscalização do Serviço de Inspeção Estadual e Federal, onde pode-se observar que $100 \%$ das amostras artesanais de queijo minas frescal demonstraram a presença de coliformes fecais, sendo a mesma porcentagem encontrada nas amostras inspecionadas.

Das 30 amostras de queijo artesanal $5(16,6 \%)$ apresentaram-se dentro do padrão e $25(83,3 \%)$ fora, enquanto que para o queijo inspecionado, 10 (33,3\%) estavam dentro e $20(66,7 \%)$ fora. Pode-se observar um número muito alto de amostras (45 ou $75 \%$ ) que não se enquadram nos padrões permitidos pela Anvisa, conforme Resolução - RDC $\mathrm{n}^{\circ} 12$, de 02 de janeiro de 2001 (BRASIL, 2001), cujo padrão para o grupo dos coliformes fecais é de $\leq 5,0 \times 10 \mathrm{NMP} / \mathrm{g}$. É importante ressaltar que os coliformes fecais pertencem a um 
grupo de microrganismos que tem habitat no trato intestinal do homem e outros animais, portanto sua presença neste alimento garante contato direto do produto com fezes, evidenciando assim o risco para a saúde dos consumidores, devido a alta patogenicidade do microrganismo.

Em trabalho semelhante, OLIVEIRA et al . (1998) analisaram 32 amostras de queijo minas frescal, inspecionadas pelo Serviço de Inspeção Federal, observaram níveis bem inferiores aos apresentados no presente trabalho, 9,4\% das amostras fora do padrão permitido para o produto.

Com relação ao padrão permitido quanto a coliformes fecais, no caso do queijo artesanal o percentual obtido por RoDRIGUEs et al . (1995), foi semelhante ao encontrado no presente trabalho, pois verificaram que $89,2 \%$ das amostras de queijo minas frescal comercializados em Viçosa, MG, apresentaram números de coliformes fecais acima do limite permitido pela legislação. Os autores atribuíram este resultado ao fato da maioria das amostras serem provenientes de fabricação artesanal. EntretantoCRUZ et al. (1992) encontraram percentuais superiores aos já mencionados, pois $98,1 \%$ das amostras de queijo minas frescal, por eles analisadas, apresentaram-se acima do padrão máximo estabelecido para coliformes fecais.

Quanto a pesquisa de Staphylococcus coagulase positiva, foram demonstrados na tabela 2 , os resultados obtidos para a presente amostragem os valores variaram de $<1,0 \times 10^{2} \mathrm{UFC} / \mathrm{g}$ a $>5,0 \times 10^{1} \mathrm{UFC} / \mathrm{g}$, sendo que 6 das 30 amostras $(20 \%)$ e 3 das 30 amostras $(10 \%)$, respectivamente, das amostras artesanais e inspecionadas, ambas apresentando valores superiores aos estabelecidos pela legislação vigente. As

Tabela 1 - Número mais provável (NMP/g) de coliformes fecais e número de amostras de queijo Minas Frescal, produzidos artesanalmente e inspecionado com fiscalização do Serviço de Inspeção Estadual e Federal, colhidas no Município de Jaboticabal, SP, durante o período de julho a dezembro de 2002.

\begin{tabular}{lcc}
\hline $\begin{array}{l}\text { NMP } / g \text { de } \\
\text { Coliformes fecais }\end{array}$ & $\begin{array}{c}\text { Amostras } \\
\text { artesanais }\end{array}$ & $\begin{array}{c}\text { Amostras } \\
\text { inspecionadas }\end{array}$ \\
\hline $0,3 \times 10^{0}$ & 1 & 4 \\
$0,3 \times 10^{0} \neg 5,0 \times 10^{2}$ & 4 & 6 \\
$5,0 \times 10^{2} \neg 5,0 \times 10^{4}$ & 7 & 8 \\
$5,0 \times 10^{4} \neg 5,0 \times 10^{6}$ & 6 & 6 \\
$5,0 \times 10^{6} \neg 5,0 \times 10^{8}$ & 10 & 4 \\
$5,0 \times 10^{8} \neg 5,0 \times 10^{10}$ & 0 & 2 \\
$>5,0 \times 10^{10}$ & 2 & 0 \\
\hline Total & 30 & 30 \\
\hline Anvisa
\end{tabular}

Anvisa: $\leq 5,0 \times 10^{2} \mathrm{NMP} / \mathrm{g}$ demais amostras não apresentaram este microrganismo.

SILVA (1998), em trabalho semelhante, verificou que em 60 amostras de queijo minas frescal examinadas na Cidade do Rio de Janeiro, RJ, 38,4\% das amostras apresentaram contagem deStaphylococcus aureus superiores a $10^{3} \mathrm{UFC} / \mathrm{g}$, enquanto MANDIL et al. (1993) constataram que $67 \%$ das amostras do mesmo produto apresentaram contagens do mesmo microrganismo variando de $10^{1}$ a $10^{6} \mathrm{UFC} / \mathrm{g}$.

Valores superiores ao padrão aceitável para Staphylococcus coagulase positiva (valores médios de $\left.7,8 \times 10^{5} \mathrm{UFC} / \mathrm{g}\right)$, foram encontrados por WENDPAP \& Rosa (1993) quando estes avaliaram a presença do agente no queijo minas frescal consumido no Município de Cuiabá, MT, onde foram obtidas cinco amostras de queijo, sendo que cada unidade amostral serviu de base para três repetições.

Não foi verificada a presença de Salmonella spp. nas amostras analisadas, sendo este resultado satisfatório por apresentar-se dentro dos padrões estabelecidos pela Anvisa (BRASIL, 2001).

Dıonizio et al . (2003) observaram resultado semelhante ao deste trabalho em relação a presença de Salmonella spp. as 20 amostras analisadas (8 de queijo minas frescal e 12 de requeijão em barra) demonstraram ausência para tal microrganismo, os autores atribuem tal fato pela grande multiplicação de coliformes nos meios seletivos para Salmonella spp.

A Anvisa estabelece a ausência de Listeria monocytogenes em $25 \mathrm{~g}$ de queijo minas frescal. Os resultados obtidos neste trabalho revelaram que todas as amostras apresentaram-se dentro dos padrões estabelecidos. Resultado semelhante foi obtido por PERESI et al. (2001), que não isolou o agente acima citado nas 60 amostras analisadas.

Tabela 2 - Número de amostras de queijo Minas Frescal, produzidos artesanalmente e com fiscalização do Serviço de Inspeção Estadual e Federal, quanto a presença de estafilococos coagulase positiva e negativa, colhidas no Município de Jaboticabal, SP, durante o período de julho a dezembro de 2002.

\begin{tabular}{lcc}
\hline $\begin{array}{l}\text { UFC/g de } \\
\text { Staphylococcus }\end{array}$ & $\begin{array}{l}\text { Amostras } \\
\text { artesanais }\end{array}$ & $\begin{array}{c}\text { Amostras } \\
\text { inspecionadas }\end{array}$ \\
\hline$<1,0 \times 10^{2}$ & 0 & 0 \\
$1,0 \times 10^{2} \neg 5,0 \times 10^{2}$ & 0 & 0 \\
$5,0 \times 10^{2} \neg 5,0 \times 10^{3}$ & 0 & 2 \\
$5,0 \times 10^{3} \neg 5,0 \times 10^{4}$ & 4 & 0 \\
$>5,0 \times 10^{4}$ & 2 & 1 \\
\hline Total & 6 & 3 \\
\hline
\end{tabular}

Anvisa: $\leq 5,0 \times 10^{2}$ 
Ainda que a legislação não contemple a presença de Campylobacter spp., mas devido sua importância na indústria alimentícia, pesquisou-se sua presença, porém não houve o isolamento de tal microrganismo nas amostras analisadas. FRANCO (1995), cita que o Campylobacter jejuni está presente nos alimentos em número reduzido após terem sidos submetidos a condições adversas, como a salga.

\section{CONCLUSÕES}

Onúmero elevado de amostras artesanais $(66,7 \%)$ e inspecionadas $(86,7 \%)$ em desacordo com a legislação, demonstram a má qualidade higiênico-sanitária destes e a necessidade de efetiva fiscalização pelos órgãos competentes, uma vez que estes valores podem propiciar a ocorrência de doenças transmitidas por alimentos (DTAs).

\section{REFERÊNCIAS}

Almeida Filho, E. S. Características microbiológicas do queijo tipominasfrescal produzidoartesanalmenteecomercial izado no M unicípio de Poços deCaldas-M G . 1999. 60p. Dissertação (Mestrado) - Faculdade de Ciências Agrárias e Veterinárias Campus de Jaboticabal, Unesp, Jaboticabal, 1999.

ANUALPEC. Mudança de escala na pecuária de leite. A nuário da Pecuária Brasileira. p.223-230, 1998.

American Public Health Association (APHA). Committe on Microbiologycal Methods for Foods.Compendiun of $\mathrm{M}$ ethods for the M icrobiologycal Examination of Foods. Washington: APHA, 1992. 129p.

BRASIL. Ministério da Saúde. Revoga portaria n. 451, de 19 de setembro de 1997. Resolução - RDC n. 12, 2 de janeiro de 2001. Diário O ficial da U nião, Poder Executivo, de 10/01/2001, Brasília, 2001. Art. 4a , p. 1-48.

BRASIL. Ministério da Agricultura e do Abastecimento. Secretaria da Defesa Agropecuária. Departamento de Inspeção de Produtos de Origem Animal. Regulamentos Técnicos de Identidade e Qualidade do leite e produtos lácteos. Portaria $\mathrm{n}^{\circ} 352$ de 04 de setembro de 1997. Diário O ficial da União de 08/09/1997, seção 01, p.19684. Brasília, 1997.

CÂmara,S.A.V.; Amaral, G.B.; Muller, M.T.; Silveira, K.C.S.; Almeida, T.N. De; Medeiro, C.F. Avaliação microbiológica de queijo tipo minas frescal artesanal, comercializados no mercado municipal de Campo Grande, Mato Grosso do Sul. Revista H igieneA Iimentar, v.16, n.101, p.32-36, 2002.

Carvalho, A.C.F.B. Isolamento eidentificação deCampylobacter spp. Em fezes diarréicas desuínos na região de Ribeirão Preto, SP. A spectos da Patogenicidade. 1992. 72p. Tese (Doutoradoem Microbiologia) - Instituto de Ciências Biomédicas, Universidade de São Paulo, São Paulo, 1992.

CRUZ, E.L.S.; Loureiro, L.F.S.; Bastos, J.A.; FAVARIM, V.C.; Tibana, A. Avaliação das condições higiênico-sanitári- as do queijo tipo minas frescal comercializado no Rio de Janeiro e em alguns pontos de seu processamento. In: CONGRESSO BRASILEIRO DE CIÊNCIAS E TECNOLOGIA DE ALIMENTOS, 14., 1992, São Paulo. A nais. São Paulo: 1994. p.134.

Dionizio, F.L.; Valle, R.H.P.; Marques, S.C.; Mendonça, A.T.; BoarI, C.A.; Freitas, R.F. Presença de Salmonella sp. em queijos minas frescal e requeijão em barras produzidos artesanalmente na região de Salinas, norte de Minas Gerais. In: CONGRESSO LATINO-AMERICANO DE HIGIENISTASDE ALIMENTOS, I., CONGRESSO BRASILEIRO DE HIGIENISTAS DE ALIMENTOS, 7., 2003, Belo Horizonte. A nais. São Paulo, 2003. p.57.

Franco, R.M. Diferentes métodos de isolamento de Campylobacter jejuni em alimentos.RevistaBrasileira de Ciência V eterinária, v.2, n.3, p. 91-96, 1995.

Franco, R.M. \& AlmeidA, L.E.F. Avaliação microbiológica de queijoralado, tipo parmesão, comercializado em Niterói, RJ. Revista H igiene A limentar, v.6, n.21, p.33-36, 1992.

Mandil, A.; Morais, V.A.D.; Pereira, M.L.; Fagundes, J.M.S.; Carmo,L.S.; Correia, M.G.; CASTRo, E.P.; Gomes,M.J.V.M. Avaliação da qualidade microbiológica de queijos comercializados em Belo Horizonte, MG, no período de 1984 a 1991. In: ENCONTRO NACIONAL DE ANALISTASDE ALIMENTOS, 8., 1993, Porto Alegre. A nais. Porto Alegre, 1993.

Oliveira, C.A.; Moreno, J.F.G.; Mestieri, L.; Germano, P.M.L. Características físico-químicas e microbiológica de queijos minas frescal e mussarela, produzidos em algumas fábricas de laticínios do estado de São Paulo. Revista H igiene A limentar, v.12, n.55, p.31-35, 1998.

Pereira,M.L.; Gastelois,M.C.A; Bastos,E.M.AF.; Caiaffa, W.T.; FALEIRO, E.S.C. Enumeração de coliformes fecais e presença deSalmonellasp. em queijo minasA rquivoBrasileiro de M edicina V eterinária eZ ootecnia, v. 51, n. 5, 1999.

Peresi, J.I.M.; Gaciano, R.A.S.; Almeida, I.AZ.C.; Lima, S.I.; Ribeiro, A.K.; Carvalho, I.S. Queijo Minas Frescal artesanale industrial: qualidade microscópica e teste de sensibilidade aos agentes antimicrobianosR evista Higiene A limentar, v.15, n.83, p.63-70, 2001.

RoDRIGUES, F.T. Características microbiológicas de queijo tipo minas frescal comercializado em Viçosa, MG. In: CONGRESSO NACIONAL DE LATICÍNIOS, 8., 1995, Juiz de Fora. A nais. Juiz de Fora, 1995. p.233-235.

Sena, M.J.; Cerqueira, M.M.O.P.; Morais, C.F.A.; CorrêA, E.S.; SouZA, M.R. Características físico-químicas de queijo de coalho comercializado em Recife-PER evista H igiene A limentar, v.14, n.74, p.41-44, 2000.

SILVA, C.A.M. Avaliação da qualidade microbiológica de queijo minas frescal consumido na cidade do Rio de Janeiro. In: CONGRESSO BRASILEIRO DE CIÊNCIAS E TECNOLOGIA DE ALIMENTOS, 17., 1998, Fortaleza. A nais. Fortaleza, 1998. p.134.

WendPap, L.L. \& Rosa, O.O. Presença de Staphylococcus aureus em queijo minas consumido no Município de Cuiabá, MT. Revista H igieneA limentar, v.7, n.27, p.2329, 1993.

Recebido em 2/3/06 Aceito em 18/5/06 